\title{
Long-term movement patterns of tiger sharks Galeocerdo cuvier in Hawaii
}

\author{
Carl G. Meyer ${ }^{1, *}$, Timothy B. Clark ${ }^{2}$, Yannis P. Papastamatiou ${ }^{1,2}$, \\ Nicholas M. Whitney ${ }^{2,3}$, Kim N. Holland ${ }^{1}$ \\ ${ }^{1}$ Hawaii Institute of Marine Biology, University of Hawaii at Manoa, P.O. Box 1346, Coconut Island, Kaneohe, \\ Hawaii 96744, USA \\ ${ }^{2}$ Department of Zoology, Edmonson Hall, University of Hawaii at Manoa, Honolulu, Hawaii 98822, USA \\ ${ }^{3}$ Present address: Center for Shark Research, Mote Marine Laboratory, 1600 Ken Thompson Parkway, Sarasota, \\ Florida 34236, USA
}

\begin{abstract}
Little is known about the long-term movement patterns of most marine apex predators. A network of acoustic receivers was used to quantify the long-term movements of transmitterequipped tiger sharks Galeocerdo cuvier Péron \& Lesueur, 1822 in the Main Hawaiian Islands. Tiger sharks were wide-ranging, swam between islands and patrolled up to $109 \mathrm{~km}$ of contiguous coastline. Visits to specific acoustic receiver sites were typically brief (mean duration $3.3 \mathrm{~min}$ ), unpredictable and interspersed by absences of weeks, months or years. This pattern may be an optimal foraging strategy for capturing risk-averse prey. Tiger sharks may have to move on soon after arriving in an area because the element of surprise is quickly lost and potential prey become wary and difficult to catch. Juvenile tiger sharks were significantly wider-ranging and less frequently detected than mature females. Juveniles may be avoiding predation by larger individuals, or exploring to find suitable home ranges. Tiger sharks may also switch movement patterns and foraging strategies to take advantage of different prey types, restricting their movements to exploit seasonally abundant and naïve prey. Further empirical studies are required to directly link movement patterns with foraging.
\end{abstract}

KEY WORDS: Acoustic telemetry $\cdot$ Foraging strategies $\cdot$ Predator-prey interactions Resale or republication not permitted without written consent of the publisher

\section{INTRODUCTION}

The tiger shark Galeocerdo cuvier is a large (up to $5.5 \mathrm{~m}$ total length, TL) apex predator found in tropical and warm-temperate waters worldwide (Compagno 1984). Tiger sharks occur in a wide variety of marine habitats, including those associated with continental shelves, oceanic islands and atolls, and also range extensively into open-ocean (Compagno 1984, Kohler et al. 1998, 1999, Holland et al. 1999). Tiger sharks are opportunistic predators that consume a diverse array of taxa-including teleosts, elasmobranchs, mollusks, crustaceans, reptiles, mammals and birds-and exhibit a clear ontogenetic shift in diet, with both prey diversity and size increasing with tiger shark size (Simpfendorfer 1992, Lowe et al. 1996). In Hawaii, small $(<2.3 \mathrm{~m}$ TL) tiger sharks feed primarily on reef fishes and cephalopods, whereas larger individuals consume a more diverse array of larger prey, including elasmobranchs, turtles, mammals and crustaceans (Lowe et al. 1996).

Large size, diverse diet and consumption of large prey makes tiger sharks a potential threat to humans, and they are one of the shark species most frequently implicated in attacks on humans, having been positively identified in 145 attacks worldwide (International Shark Attack File 2008, http://www.flmnh.ufl.edu/fish/ Sharks/ISAF/ISAF.htm. Accessed November 22, 2008). Although shark attacks are extremely rare overall, the few that do occur are often widely publicized by the media, resulting in heightened public fear and calls for management actions to increase public safety (Wetherbee et al. 1994). Shark attacks that occurred in Hawaii during the latter half of the twentieth century resulted in 
a series of shark culling programs aimed at reducing shark attack risk by removing large tiger sharks from coastal waters (Wetherbee et al. 1994). However, these control programs were discontinued after empirical studies showed that underlying assumptions of tiger shark site attachment to restricted coastal areas were incorrect (Holland et al. 1999). Like shark culling programs, ocean use guidelines aimed at modifying human behaviour to reduce shark attack risk are also based on assumptions about shark movement patterns and foraging strategies. For example, one common recommendation for reducing the risk of shark attack is to 'stay out of the water at dawn, dusk and night when some species of sharks move inshore to feed' (Baldridge 1974). However, most $(67 \%)$ shark attacks in Hawaii occur during daytime between 10:00 and 16:00 h (International Shark Attack File 2008, http://www.flmnh.ufl.edu/fish/Sharks/ISAF/ISAF. htm. Accessed November 22, 2008), coinciding with peak time for in-water recreational activities (Meyer 2007). Clearly a better understanding of the long-term movement and habitat use patterns of tiger sharks is required in order to provide science-based guidelines for shark attack risk assessment along populated coastlines.

Previous studies have quantified tiger shark movements, habitat use and foraging strategies across a range of spatial and temporal scales. Mark-recapture studies and satellite tagging have shown that some tiger sharks move very long distances (up to $8000 \mathrm{~km}$ ) including across ocean basins (Kohler et al. 1998, 1999, Heithaus et al. 2007). Tiger shark catch rates vary seasonally at the latitudinal extremes of their distribution, indicating that seasonal migrations may occur in some areas (Heithaus 2001, Wirsing et al. 2006). Short-term (up to $50 \mathrm{~h}$ ), active tracking of tiger sharks equipped with acoustic transmitters revealed direct movements of up to $35 \mathrm{~km}$ across a $500 \mathrm{~m}$ deep channel between oceanic islands, orientation to the bottom in depths $<300 \mathrm{~m}$ and to the mixed layer (0 to $80 \mathrm{~m}$ ) in deeper waters with occasional brief dives as deep as $335 \mathrm{~m}$ (Holland et al. 1999). Short (up to $11 \mathrm{~h}$ ) acoustic tracks of tiger sharks equipped with video cameras suggest that tiger sharks select habitats where prey are most abundant and utilize stealth as their primary foraging tactic (Heithaus et al. 2002). Collectively these studies suggest that tiger sharks probably occupy very large home ranges, within which they employ specific localized patterns of movement and habitat use that reflect foraging tactics.
We currently lack long-term movement and habitat use data required to understand the relationship between tiger shark utilization of extremely large home ranges and their fine-scale movement patterns. This information could also help to clarify how tiger shark movement patterns are related to the rare incidences of shark attacks on humans. We used a network of acoustic receivers to empirically quantify tiger shark long-term movement patterns along a populated coastline in Hawaii, and address 4 questions about their spatial dynamics: (1) Do tiger sharks show long-term fidelity to coastal sites? (2) Is there significant spatial and temporal overlap in longterm habitat use among individual sharks? (3) Do tiger sharks exhibit predictable temporal (diel, lunar \& seasonal) patterns of movement? (4) Do tiger shark movement and habitat use patterns correspond with the spatial and temporal patterns of shark attacks on humans?

\section{MATERIALS AND METHODS}

Study area. The study area included 4 volcanic high islands (Oahu, Maui, Kahoolawe and Hawaii), spanning $400 \mathrm{~km}$ at the SE end of the Hawaiian Archipelago (Fig. 1). These islands range in size from 116 to

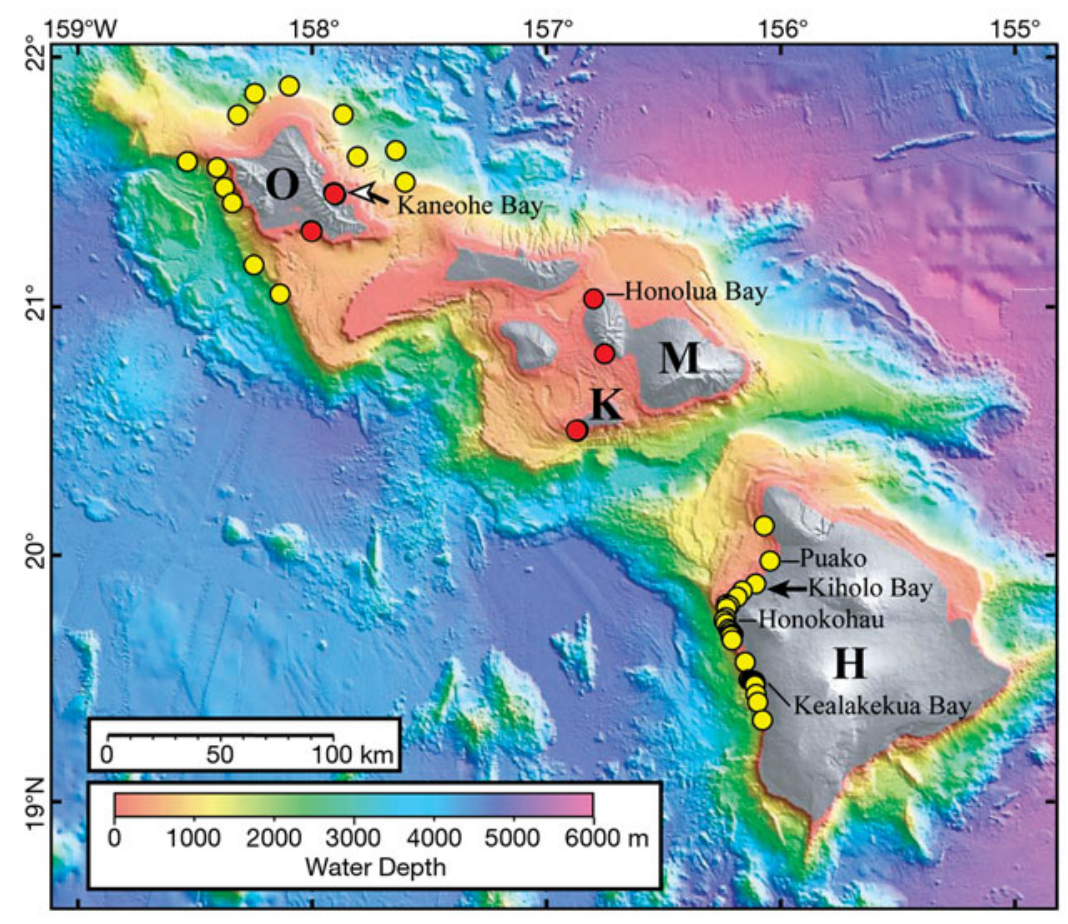

Fig. 1. Locations of acoustic receivers (colored circles) around the Hawaiian Islands of Oahu (O), Maui (M), Kahoolawe (K) and Hawaii $(\mathrm{H})$. (O) Receivers in place throughout the entire study period (3 December 2003-17 June 2007); (O) receivers deployed for only part of the study period. See description in 'Materials and methods: Listening array design and duration of monitoring' and Table 1 for additional details 
$10458 \mathrm{~km}^{2}$ and each is separated from its nearest acoustic receiver-arrayed neighbor by distances ranging from 11 to $100 \mathrm{~km}$. Oahu, Maui and Hawaii are heavily populated, and ocean recreation activities occur year round, whereas Kahoolawe is currently uninhabited. The west coast of Hawaii Island was the primary focus of tiger shark tagging and subsequent acoustic monitoring (see below).

VR2 listening array. Acoustic monitoring system: The Vemco ${ }^{\mathrm{TM}}$ VR2 acoustic monitoring system was used to track tiger shark movements in Hawaiian waters. This system consists of small $(340 \mathrm{~mm}$ long $\times$ $60 \mathrm{~mm}$ diameter, weight in water $300 \mathrm{~g}$ ), self-contained, single channel $(69 \mathrm{kHz})$ underwater receivers that listen continually for the presence of coded-pulse acoustic transmitters. Sharks were equipped with Vemco V16-6H transmitters $(16 \times 94 \mathrm{~mm}$, weight in water $14 \mathrm{~g}$ ) with a battery life of approximately $732 \mathrm{~d}$. These transmitters periodically emit a 'pulse train' of closely spaced $69 \mathrm{kHz}$ 'pings', which uniquely identify each shark. These pulse trains are typically $3.1 \mathrm{~s}$ in length (R04K code map), and the transmitters were silent for a randomized period of 10 to $35 \mathrm{~s}$ between each pulse train. Each successfully decoded pulse train is recorded as a single detection by a VR2 receiver and stored in the receiver memory as the unique transmitter number, date and time of detection. Detection ranges were empirically determined by deploying transmitters from a skiff equipped with an onboard GPS-equipped Vemco VR100 receiver and hydrophone. The skiff was positioned over each receiver and then allowed to slowly drift up to $1.5 \mathrm{~km}$ away. The VR100 receiver recorded the time and position of each transmission. The originating positions of transmissions logged by the underwater VR2 receivers during range tests were subsequently determined by cross referencing VR2 and VR100 logs. Detection range was up to $957 \mathrm{~m}$.

Listening array design and duration of monitoring: The listening array consisted of 61 acoustic receivers arranged in several constellations in coastal waters around the islands of Hawaii, Maui, Kahoolawe and Oahu (Fig. 1). Receivers were deployed by several researchers independently studying movements of a variety of taxa including teleosts, elasmobranchs and turtles (Table 1). These constellations collectively formed a spatially nested array capable of detecting movements of acoustically tagged sharks across distances ranging from several hundred meters along contiguous coastline to several hundred kilometers between islands. Monitored habitats included shallow ( 2 to $15 \mathrm{~m}$ ) embayments ( $\mathrm{N}=13$ receivers), coastal fringing reefs ( $\mathrm{N}=26$ receivers), sandy fore reef (20 to $30 \mathrm{~m})(\mathrm{N}=6$ receivers $)$, the edge of a deepwater $(140 \mathrm{~m})$ bank ( $\mathrm{N}=3$ receivers $)$ and fish aggregation devices

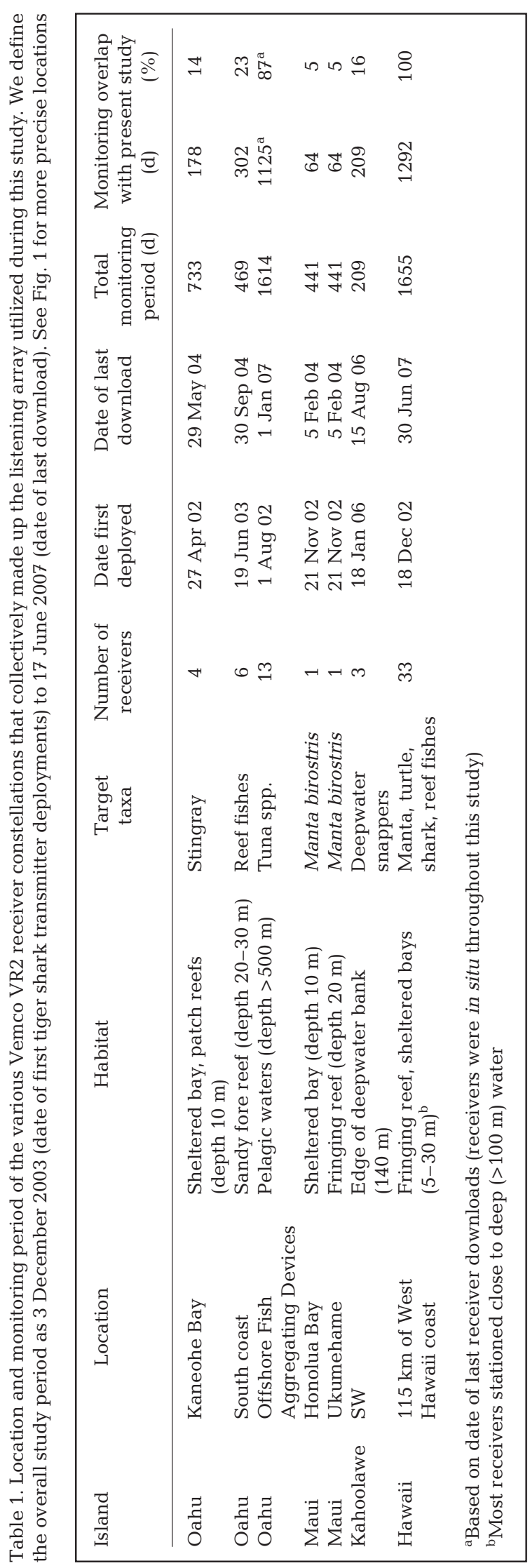


(FAD, moored buoys) anchored 5 to $25 \mathrm{~km}$ offshore in 565 to $2480 \mathrm{~m}$ of water ( $\mathrm{N}=13$ receivers) (Table 1 ).

The overall monitoring period was $1292 \mathrm{~d}$ from the date of the first transmitter deployments (3 December 2003) until the last receiver downloads (17 June 2007), and spanned the predicted maximum transmitter battery life (732 d) of all transmitters implanted into tiger sharks captured during this study. The west Hawaii Island and Oahu offshore FAD receiver constellations were in situ throughout the entire study period (Table 1). Other components of the listening array were deployed for shorter periods and partially overlapped our monitoring period by between 64 and $302 \mathrm{~d}$ ( 5 to $23 \%$ overlap). Monitoring coverage was most limited (fewest receivers, shortest monitoring periods) around the islands of Maui and Kahoolawe (Fig. 1, Table 1).

Shark capture and transmitter deployments. Sharks were captured using demersal longlines baited with large tuna heads and fish scraps, and soaked for 2 to $12 \mathrm{~h}$ in depths of 10 to $60 \mathrm{~m}$ (see Holland et al. 1999 for additional details of longline fishing methods). Captured sharks were brought alongside a $6 \mathrm{~m}$ skiff, where they were tail-roped and inverted to initiate tonic immobility. Sharks remained docile in this position while transmitters were surgically implanted into the body cavity through a small incision in the abdominal wall (as per Holland et al. 1999). Following transmitter insertion the incision was closed with interrupted sutures, and each shark was tagged with an external identification tag (Hallprint ${ }^{\mathrm{TM}}$ stainless steel dart 'wire through' tags). The hook was then removed and the shark released. The entire handling process took less than 20 min and all sharks swam away vigorously on release.

Data analyses. Influence of shark size and maturity on movements: We evaluated whether size or maturity status influenced tiger shark movements by dividing sharks into juvenile and adult subgroups and comparing their detection patterns. Sharks were assigned to each group using size at first reproduction (SFR) estimates derived from Hawaiian tiger sharks (male SFR = $292 \mathrm{~cm}$ TL, female SFR = $330 \mathrm{~cm}$ TL, Whitney \& Crow 2007). $t$-tests were used to compare mean juvenile and adult: (1) maximum distance detected away from capture site, (2) total number of detections, (3) number of days detected, and (4) time elapsed between the first and last detections (detection span).

Spatial analyses: A null model was used to determine whether overlap in space utilization between individual tiger sharks was significantly different from that expected by chance. Each acoustic receiver was treated as a 'resource state' in the model, which generated pseudo-communities of randomly re-shuffled resource states, and compared simulated overlap values with observed values (Connor \& Simberloff
1979). As such, the null model determines statistical significance $(\alpha \leq 0.05)$ for the standard overlap index. The number of calendar days each shark was detected by each receiver was used as the metric of resource state use. It was assumed that this would be the best measure of long-term use patterns because raw total transmitter detections cannot be used to differentiate between a shark that visited a receiver station only once but remained within detection range for multiple hours, versus a shark that visited on multiple days for shorter periods. Where the model indicated significant spatial overlap, data were further examined to determine whether sharks were visiting the receiver stations on the same day (i.e. whether sharks were also overlapping temporally). Ecosim 7.0 (Gotelli \& Entsminger 2004) was used to generate the null model and run 1000 simulations using the RA3 algorithm, which includes the Pianka overlap index. The Pianka index calculates the degree of overlap between individuals (in our case, the number of days sharks were detected at receivers) generating a value that ranges between 0 (no spatial overlap between individuals) and 1 (100\% spatial overlap). A statistically significant result indicates 2 sharks spent similar amounts of time at the same receivers.

To further quantify the movement patterns of individual tiger sharks along the west coast of Hawaii Island, movements among receivers were reduced to a single dimension (north-south, the primary axis of the coastline), and plotted as time series of successive distances moved between each detection. Plots were normalized to the capture site (i.e. Kiholo Bay =0), with movements south of this location given a negative value and movements north given a positive value. This provided a simple graphical method for determining the scale and frequency of shark movements back and forth along the $109 \mathrm{~km}$ section of instrumented coastline (reduced to $86 \mathrm{~km}$ in a single north-south dimension).

Temporal analyses: Abacus plots of daily detections were examined for visually obvious temporal patterns in tiger shark movements and Fast Fourier Transformations (FFTs) with Hamming window smoothing were used to search for cyclical patterns in tiger shark detections along the west Hawaii Island coast (Graham et al. 2006, Meyer et al. 2007a). An FFT decomposes time-series data into component frequencies and then searches the data for sinusoidal patterns. The frequencies of dominant patterns are identifiable as peaks within a frequency power spectrum (see Chatfield 2003). Two FFT search strategies were used: (1) longterm cycles (e.g. lunar) were investigated by pooling all detections of each shark by calendar day between the dates of transmitter deployment and the later of either predicted transmitter battery death date or last detection; and (2) shorter cycles (diel, crepuscular and 
tidal) were assessed by pooling data for each individual into hourly bins.

The duration of tiger shark visits to each receiver location was quantified by calculating the time elapsed between the first and last transmitter detections during each visit. A visit started and ended when either the location changed or the transmitter was not detected for $30 \mathrm{~min}$. Visits consisting of single transmitter detections were considered to last $1.2 \mathrm{~min}$ (equivalent to the transmitter pulse train duration of $3.1 \mathrm{~s}$, preceded and followed by listening periods equivalent to the maximum random off time of $35 \mathrm{~s}$ ). The time elapsed between consecutive visits was used to determine how long each shark was absent from its most frequently visited location.

\section{RESULTS}

\section{Size and sex of transmitter-equipped sharks}

Between December 2003 and December 2004, 13 tiger sharks were captured in Kiholo Bay (Hawaii Island, Fig. 1), and implanted with V16 transmitters (Table 2). In January 2005, 2 additional tiger sharks were opportunistically captured inside Kaneohe Bay (Oahu, Fig. 1) and implanted with transmitters (Table 2). Sharks captured were primarily sexually mature females ( 7 of 15 sharks) and immature sharks (4 female, 3 male) (Table 2). One sexually mature male tiger shark was captured and tagged but never detected (Table 2). There were significant differences between the movement patterns of mature female and juvenile tiger sharks (see below).

\section{Passive monitoring}

Between December 2003 and June 2007, 42 (69\%) of 61 receivers detected 13 (86\%) of 15 instrumented tiger sharks over periods spanning from 3 to $892 \mathrm{~d}$ $($ median $=495 \mathrm{~d})($ Table 2$)$. Each of these 42 receivers detected between 1 and 9 (median = 3) tiger sharks (Fig. 2) and the total number of days on which each shark was detected at any receiver ranged from 2 to $135 \mathrm{~d}$ (median = $46 \mathrm{~d}$ ) (Table 2). Tiger sharks were detected at all 4 islands and in every habitat type monitored by the array, and the total number of transmitter detections recorded per shark ranged from 8 to 738 (median $=227$ detections) (Table 2). Compared to juvenile tiger sharks $(n=6)$, mature female sharks $(n=7)$ were detected over significantly longer periods, on significantly more days, and had a significantly higher number of total detections (Table 3).

\section{Spatial patterns of movement}

Receivers detected inter-island movements by $6(40 \%)$ tiger sharks with straight-line distances ranging from 106 to $318 \mathrm{~km}$ (Fig. 2). Four of these sharks were detected making round trips between west Hawaii Island and either Kahoolawe, Maui or Oahu (Fig. 2). Inter-island movements were detected

Table 2. Galeocerdo cuvier. Summary of acoustic monitoring data for transmitter-equipped tiger sharks captured in Kiholo Bay (Hawaii Island, $\mathrm{N}=13$ ) and Kaneohe Bay $\left(\mathrm{Oahu}, \mathrm{N}=2^{\mathrm{a}}\right.$ ). Underlined total length (TL) indicates sharks above the size of sexual maturity, based on reproductive data from Whitney \& Crow (2007)

\begin{tabular}{|c|c|c|c|c|c|c|c|c|c|c|}
\hline $\begin{array}{l}\text { Shark } \\
\text { ID }\end{array}$ & Sex & $\begin{array}{l}\mathrm{TL} \\
(\mathrm{cm})\end{array}$ & $\begin{array}{c}\text { Tag } \\
\text { deployed }\end{array}$ & $\begin{array}{c}\text { First } \\
\text { detected }\end{array}$ & $\begin{array}{c}\text { Last } \\
\text { detected }\end{array}$ & $\begin{array}{l}\text { Days between } \\
\text { deployment \& } \\
\text { first detection }\end{array}$ & $\begin{array}{c}\text { Overall } \\
\text { detection } \\
\text { period (d) }\end{array}$ & $\begin{array}{c}\text { Total } \\
\text { years } \\
\text { spanned }\end{array}$ & $\begin{array}{c}\text { No. of } \\
\text { days } \\
\text { detected }\end{array}$ & $\begin{array}{c}\text { Total } \\
\text { detections }\end{array}$ \\
\hline TS1 & $\mathrm{F}$ & $\underline{449}$ & 3 Dec 03 & 14 Dec 03 & 20 Jan 06 & 11 & 768 & 2.1 & 73 & 227 \\
\hline TS2 & $\mathrm{F}$ & 219 & 3 Dec 03 & 31 Dec 03 & 26 Apr 04 & 28 & 117 & 0.32 & 21 & 55 \\
\hline TS3 & $\mathrm{F}$ & $\underline{355}$ & 4 Dec 03 & 12 Dec 03 & 22 Apr 05 & 8 & 497 & 1.36 & 19 & 53 \\
\hline TS4 & $\mathrm{F}$ & $\underline{460}$ & 4 Dec 03 & 10 Dec 03 & 20 Mar 04 & 6 & 101 & 0.28 & 51 & 497 \\
\hline TS5 & F & $\underline{439}$ & 26 Jun 04 & 4 Jul 04 & 2 Oct 06 & 8 & 820 & 2.25 & 90 & 656 \\
\hline TS6 & $\mathrm{F}$ & 211 & 26 Jun 04 & 27 Dec 05 & 30 Dec 05 & 549 & 3 & 0.01 & 3 & 25 \\
\hline TS7 & M & 181 & 27 Jun 04 & $12 \mathrm{Jul} 04$ & 30 Aug 06 & 15 & 779 & 2.13 & 79 & 412 \\
\hline TS8 & M & 218 & 27 Jun 04 & 16 Sep 04 & 3 Jan 06 & 81 & 474 & 1.3 & 2 & 8 \\
\hline TS9 & M & 279 & 27 Jun 04 & 13 Jul 04 & 24 Aug 04 & 16 & 42 & 0.12 & 15 & 93 \\
\hline TS10 & M & $\underline{322}$ & 29 Jun 04 & Not detected & - & - & - & - & - & - \\
\hline TS11 & $\mathrm{F}$ & $\underline{383}$ & 1 Dec 04 & 12 Dec 04 & 23 May 07 & 11 & 892 & 2.44 & 135 & 738 \\
\hline TS12 & $\mathrm{F}$ & $\underline{413}$ & 1 Dec 04 & 7 Dec 04 & 16 Apr 06 & 6 & 495 & 1.36 & 53 & 346 \\
\hline TS13 & $\mathrm{F}$ & $\underline{375}$ & 3 Dec 04 & 13 Dec 04 & 13 Feb 07 & 10 & 792 & 2.17 & 46 & 324 \\
\hline $\mathrm{TS}_{1} 4^{\mathrm{a}}$ & F & $\overline{237}$ & 12 Jan 05 & 27 Apr 05 & 5 Jun 05 & 105 & 39 & 0.11 & 4 & 10 \\
\hline $\mathrm{TS} 5^{\mathrm{a}}$ & $\mathrm{F}$ & 193 & 12 Jan 05 & Not detected & - & - & - & - & - & - \\
\hline
\end{tabular}




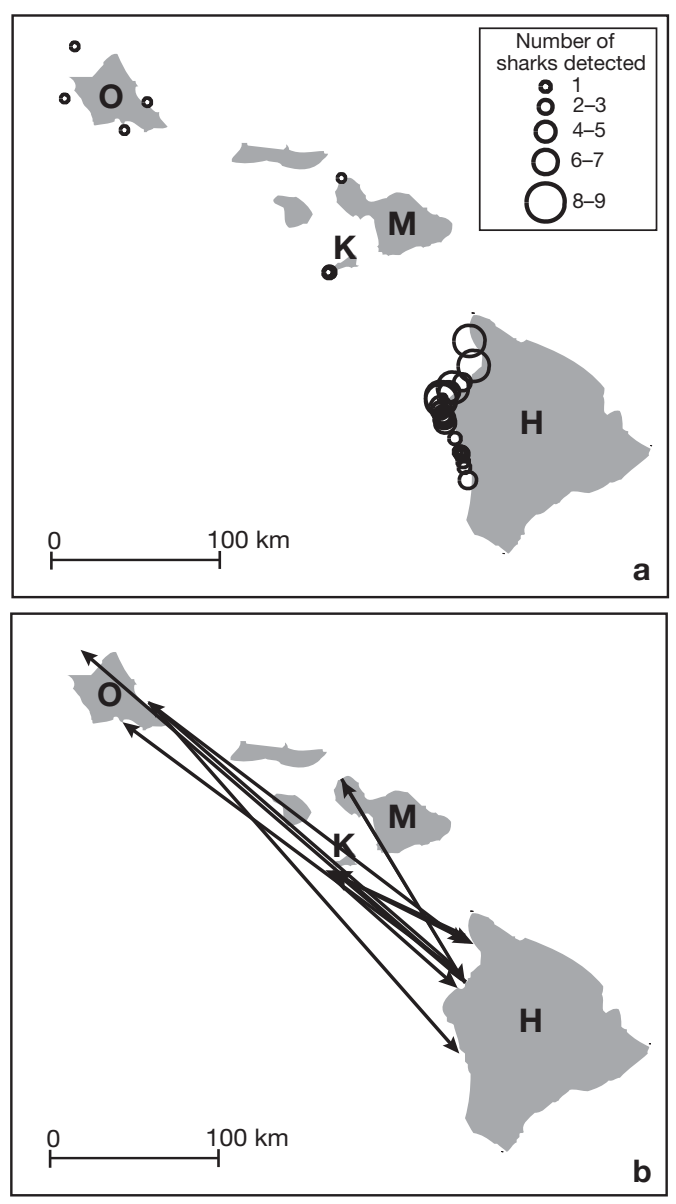

Fig. 2. Galeocerdo cuvier. (a) Number of transmitterequipped tiger sharks detected by receivers stationed around the Hawaiian Islands of Oahu (O), Maui (M), Kahoolawe (K) and Hawaii $(\mathrm{H})$. (b) Inter-island tiger shark movements (lines with arrowheads) detected by the listening array

in 4 out of 6 juvenile and 2 out of 7 mature female tiger sharks. On average, juvenile sharks were detected significantly further away from their capture locations than mature females (Table 3).

Most detections (96\%) were on receivers deployed along the west Hawaii Island coast, where 11 tiger sharks were each detected at multiple locations along sections of coastline spanning from $32 \mathrm{~km}$ to the maximum dimension of the array of 109 km (median $91 \mathrm{~km}$ ) (Figs. 2 \& 3). Coastal movements varied among sharks but most individuals exhibited periods of coastal patrolling behaviour, swimming back and forth along 15 to $109 \mathrm{~km}$ of the west Hawaii Island coastline (10 to $86 \mathrm{~km}$ along a single north-south dimension), interspersed with absences from the listening array (Fig. 4).
Three sharks also exhibited short periods (up to several days) of more restricted movements, when they were repeatedly detected along 2 to $5 \mathrm{~km}$ of coastline, often in the vicinity of Honokohau Harbor (e.g. TS4, Fig. 4).

Pianka overlap indices generated by the Ecosim model indicated a $28 \%$ spatial overlap among tiger sharks utilizing the west Hawaii Island coast, with 15 out of 54 possible interactions producing significant overlap (Table 4). Some general trends were evident, such as more frequent tiger shark detections by receivers along the northern half of the west Hawaii Island listening array, and several northern 'hotspots,' where up to 9 individual sharks were detected over the course of the study (e.g. Puako, Figs. 1-3). However, the maximum number of tiger sharks detected at any one receiver on the same day was 2 , and this only happened at 6 locations on $16 \mathrm{~d}(1.2 \%)$ out of the total 1292 d monitoring period. No sharks were detected visiting any receivers at the same time. These results indicate that despite some spatial overlap, instrumented tiger sharks were temporally and mostly spatially separated. Six large (up to $449 \mathrm{~cm} \mathrm{TL}$ ) tiger sharks were detected by receivers stationed in sheltered bays heavily used for in-water recreational activities, such as swimming and snorkeling (Kealakekua Bay, Kona Coast State Park, Honolua Bay and Kaneohe Bay, Fig. 1), but these events were rare (1 or 2 occurrences per site during the entire monitoring period).

\section{Temporal pattern of movements}

Long-term detections of individual sharks typically occurred in clusters lasting 2 to 6 mo separated by absences of up to 18 mo (Fig. 5). Possible annual rhythms were evident in the detections of 3 sharks (TS3, TS7 \& TS13) but the detection clusters of each of these sharks were centered on different months of the year (Fig. 5). Detection frequency of each shark along the west Hawaii Island coast was generally highest

Table 3. Galeocerdo cuvier. Results of $t$-tests comparing mean $( \pm \mathrm{SD})$ detection spans, total days detected, total detections and maximum detection distances of mature female $(F)$ and juvenile tiger sharks

\begin{tabular}{|lccccc|}
\hline & Mature F & Juvenile & $t$ & df & $\mathrm{p}$ \\
\hline Mean detection span (d) & $624 \pm 40$ & $243 \pm 53$ & 2.30 & 10 & 0.02 \\
Mean total days detected & $67 \pm 5$ & $21 \pm 5$ & 2.48 & 11 & 0.02 \\
Mean total detections & $406 \pm 34$ & $101 \pm 26$ & 2.75 & 10 & 0.01 \\
& & & & & \\
Mean maximum detection & $63 \pm 4$ & $183 \pm 22$ & 2.24 & 5 & 0.04 \\
$\begin{array}{l}\text { distance (km away from } \\
\text { capture location) }\end{array}$ & & & & & \\
\hline
\end{tabular}


during its season of capture (Fig. 5 \& 6). No overall synchronicity in long-term detections was evident among sharks, with some individuals being detected most frequently during periods when others were absent from the listening array (Fig. 5). FFTs revealed no lunar or other multi-day cycles in tiger shark detections, but dominant $24 \mathrm{~h}$ peaks were evident in the spectra of 4 sharks (TS1, TS4, TS5, TS11) detected most fre- quently during daytime (see Fig. 7 for comparative examples of sharks with and without dominant $24 \mathrm{~h}$ peaks). However, the signal strength of the diel rhythm was low because these sharks were also detected at night and had frequent multi-day gaps between successive visits to receiver locations (Fig. 7).

Tiger shark visits to each receiver location were typically brief, with mean visit duration varying among
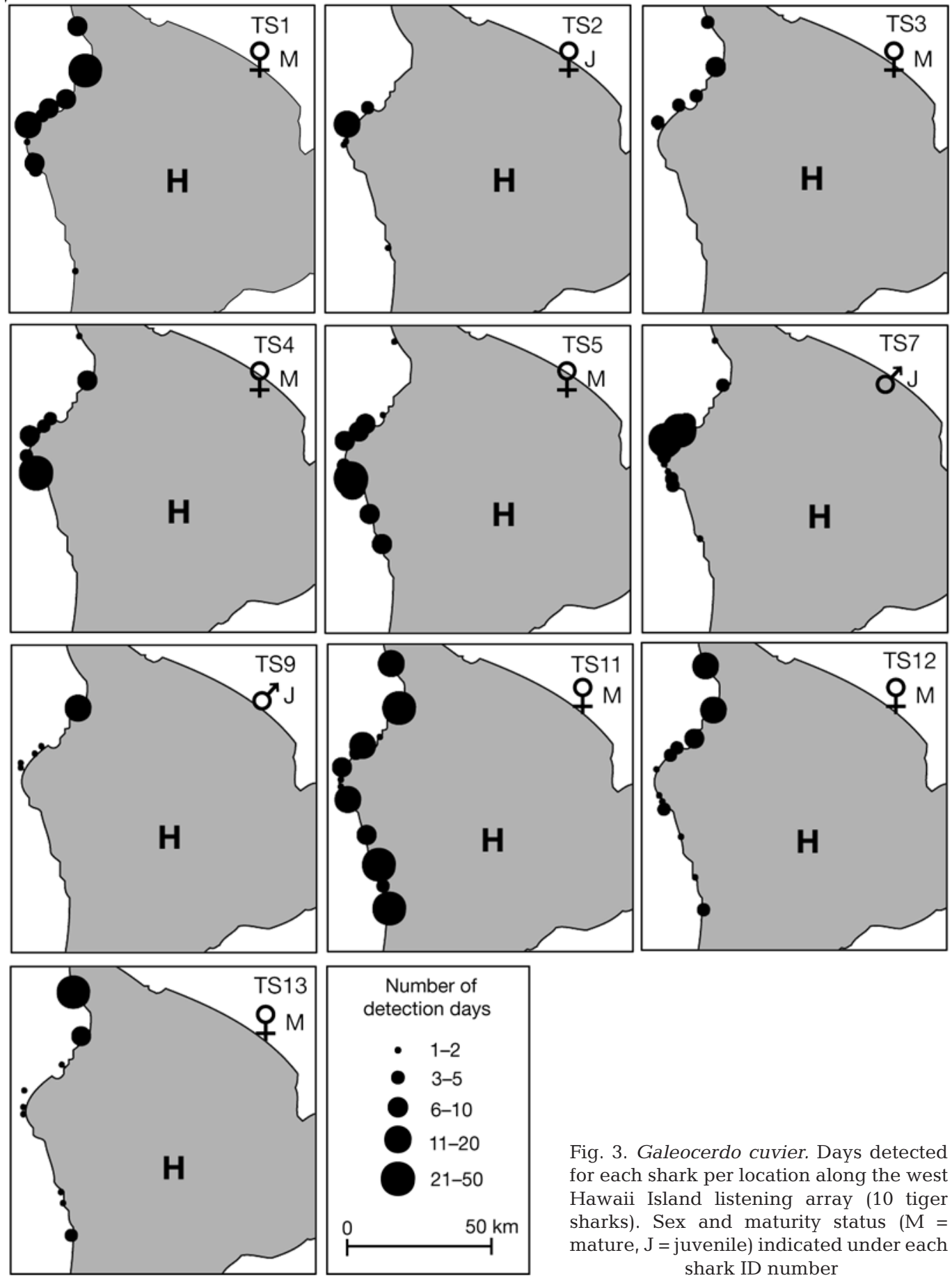

Fig. 3. Galeocerdo cuvier. Days detected for each shark per location along the west Hawaii Island listening array (10 tiger sharks). Sex and maturity status $(\mathrm{M}=$ mature, $\mathrm{J}=$ juvenile) indicated under each shark ID number 
individuals from 2.4 to $4.6 \mathrm{~min}$ (grand mean = $3.3 \mathrm{~min}$ ). The maximum length of visit varied among sharks from 8.4 to $132.7 \mathrm{~min}$. The mean duration of absence between visits to the most frequently visited sites ranged among individual sharks from 0.9 to $23.1 \mathrm{~d}$ (grand mean $=11.5 \mathrm{~d}$ ).
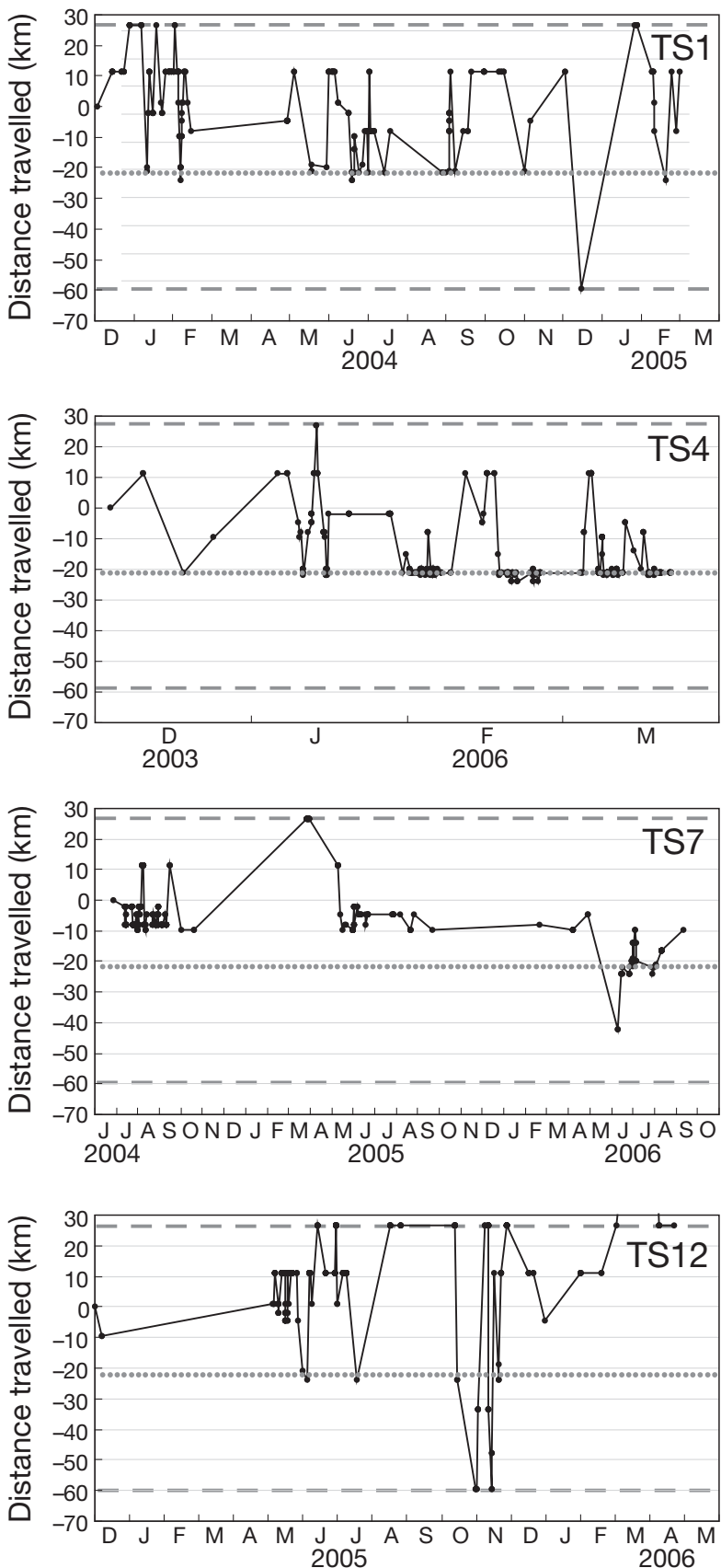

\section{DISCUSSION}

Although our sample size was small (15 sharks) and included a wide size range of both sexes, there were several broad similarities in behaviour among individuals, including relatively wide-ranging, arrhythmic
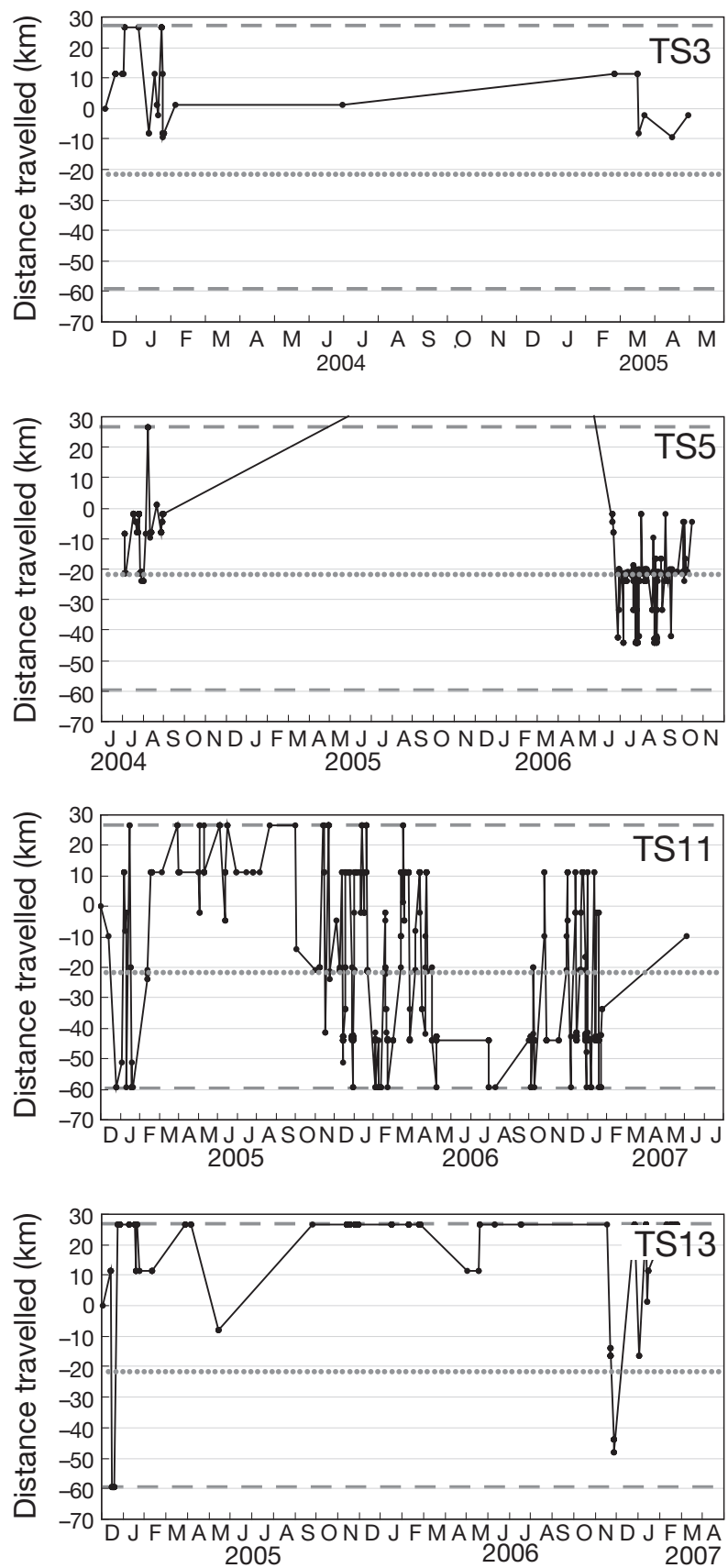

Fig. 4. Galeocerdo cuvier. Minimum 1-dimensional distance $(\mathrm{km})$ traveled by tiger sharks between successive detections $(\bullet)$ along the north-south axis of west Hawaii Island listening array. Distances are relative to capture location (Kiholo Bay $=0$ ). Dashed lines: positions of the northernmost and southernmost receiver stations along the west Hawaii Island coast. Movements beyond this indicate visits to more northerly islands. Dotted line: location of Honokohau Harbor. Note use of different scales on 
Table 4. Galeocerdo cuvier. Pianka index of spatial overlap for eleven V16 transmitter-equipped tiger sharks detected at acoustic receiver sites along the west coast of Hawaii Island. Italics: tiger shark ID numbers; bold: mature sharks; ${ }^{*}$ statistically significant overlaps as determined by a null model

\begin{tabular}{|c|c|c|c|c|c|c|c|c|c|c|c|}
\hline & TS1 & TS2 & TS3 & TS4 & TS5 & TS7 & TS8 & TS9 & TS11 & TS12 & TS13 \\
\hline TS1 & TS2 & $\begin{array}{r}0.344 \\
\text { TS3 }\end{array}$ & $\begin{array}{c}0.919^{*} \\
0.372^{*} \\
\text { TS4 }\end{array}$ & $\begin{array}{c}0.334 \\
0.160 \\
0.232 \\
\text { TS5 }\end{array}$ & $\begin{array}{c}0.338 \\
0.141 \\
0.101 \\
0.450 \\
\\
\text { TS7 }\end{array}$ & $\begin{array}{l}0.506 \\
0.638^{*} \\
0.452 \\
0.294 \\
0.396 \\
\text { TS8 }\end{array}$ & $\begin{array}{l}0.00 \\
0.00 \\
0.00 \\
0.00 \\
0.00 \\
0.00 \\
\\
\\
\text { TS9 }\end{array}$ & $\begin{array}{l}0.904^{*} \\
0.189 \\
0.824^{*} \\
0.222 \\
0.048 \\
0.324 \\
0.00 \\
\\
\text { TS11 }\end{array}$ & $\begin{array}{l}0.851^{*} \\
0.073 \\
0.780^{*} \\
0.348 \\
0.230 \\
0.298 \\
0.017 \\
0.837^{*} \\
\\
\text { TS12 }\end{array}$ & $\begin{array}{l}0.865^{*} \\
0.023 \\
0.869^{*} \\
0.208 \\
0.143 \\
0.279 \\
0.00 \\
0.795^{*} \\
0.857^{*}\end{array}$ & $\begin{array}{l}0.364 \\
0.031 \\
0.483 \\
0.060 \\
0.027 \\
0.101 \\
0.00 \\
0.211^{*} \\
0.446^{*} \\
0.611^{*}\end{array}$ \\
\hline
\end{tabular}

patterns of movement, brief visits to receiver sites and long absences between visits. These long-term movement patterns are distinctly different from those of other large, coral reef-associated predators, such as Galapagos sharks Carcharhinus galapagensis, grey reef sharks Carcharhinus amblyrhynchos and giant trevally Caranx ignobilis. These other predators consume many of the same reef-associated prey as tiger sharks (Lowe et al. 1996, Wetherbee et al. 1996, 1997, Meyer et al. 2001, Papastamatiou et al. 2006), but are often highly site-attached to well defined home ranges and exhibit predictable, rhythmic patterns of behaviour, including diel habitat shifts and seasonal lunar migrations to spawning areas (McKibben \& Nelson 1986, Lowe et al. 2006, Meyer et al. 2007a). Arrhythmic, wide-ranging tiger shark movements resulted in relatively low spatial and temporal overlap in longterm habitat use among individuals (only $23 \%$ showed significant spatial overlap, sharks were detected together at the same site on only $1.2 \%$ of monitoring days and no sharks were detected simultaneously), even though most (13 of 15) were captured at a single location. This pattern contrasts with giant trevally and other mobile reef predators such as green jobfish Aprion virescens, whose rhythmic patterns of behaviour and synchronous movements routinely result in multiple individuals being simultaneously detected in the same locations, even when fish are captured months apart (Meyer et al. 2007a,b).

Wide-ranging movements and long absences between brief visits to each location, together with the lack of strong patterns in tiger shark movements, may be a foraging strategy that prevents prey from 'anticipating' when tiger sharks will appear. Although we do not know whether sharks were actively foraging within receiver detection ranges, their behaviour was

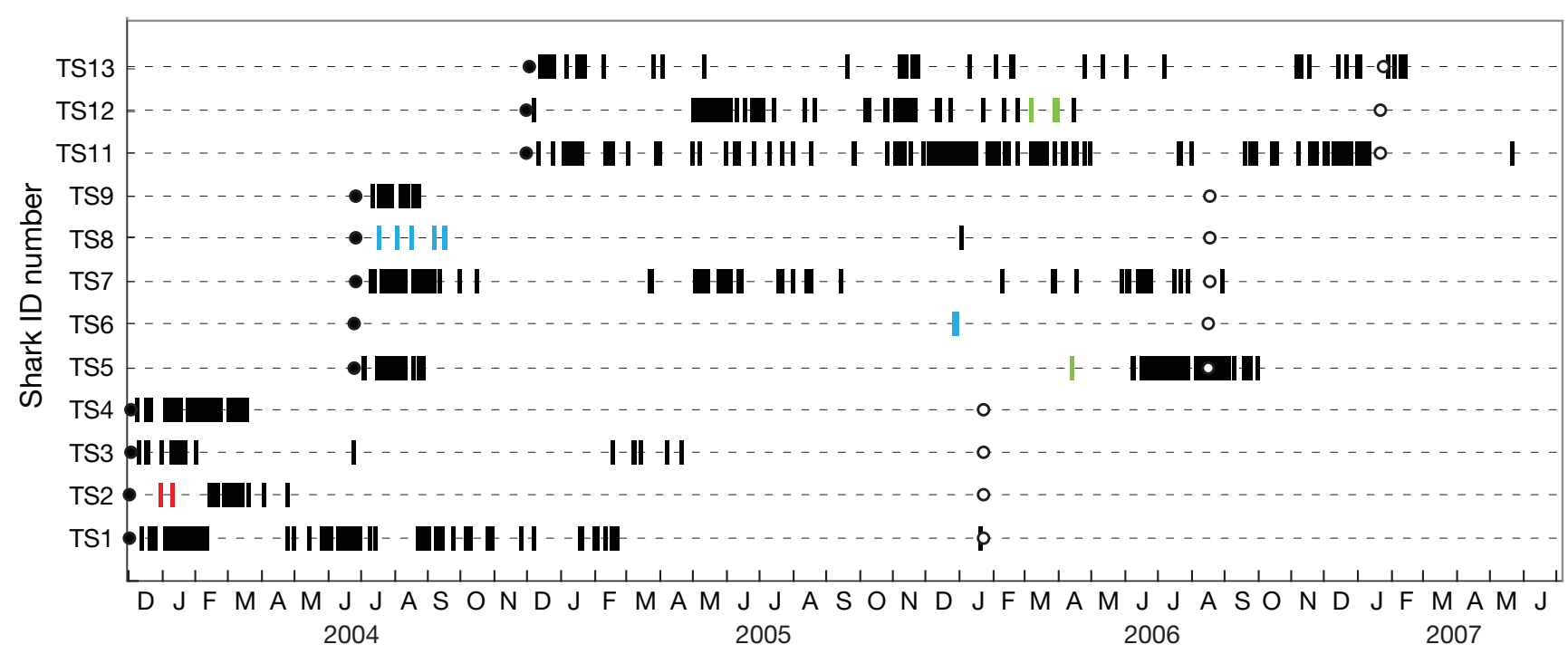

Fig. 5. Galeocerdo cuvier. Abacus plot of tiger shark detections (vertical lines = dates detected) by underwater receivers in Kahoolawe (green), Hawaii (black), Maui (red) and Oahu (blue). (•) Transmitter deployment dates; (0) predicted transmitter death dates 
consistent with a predator moving between patches where marginal value thresholds were determined by prey behaviour rather than prey abundance (Brown et al. 1999, Lima 2002). Tiger sharks consume a wide variety of mobile, reef-associated taxa (Lowe et al. 1996) and are thus unlikely to significantly deplete prey numbers in a few minutes. However, they may have to move on soon after arriving in an area because the element of surprise is quickly lost and potential prey become wary and difficult to catch. Video footage from tiger sharks equipped with dorsally mounted cameras indicates that they do not attack vigilant prey (Heithaus et al. 2002), supporting the likely importance of surprise as a tiger shark hunting tactic. We note, however, that tiger sharks may have simply been transiting between locations in the listening array, and additional empirical studies are needed to directly correlate movements with feeding activity.

Although all tiger sharks monitored during our study exhibited wide-ranging, arrhythmic movements in comparison to other reef-associated predators, there were also significant intraspecific differences between the movement patterns of juvenile and mature female sharks. Juveniles were significantly wider-ranging, less frequently detected and detected for shorter overall time spans than mature females. Our small sample size requires a cautious interpretation of these differences but most of the juvenile sharks were small enough that cannibalism might be a concern and a reason for them to avoid areas where larger sharks were foraging. Other possible explanations are that juvenile tiger sharks explore to find suitable home ranges or have a harder time obtaining resources than mature sharks and have to forage over a larger area. Juvenile dispersal is widespread in nature and common among large, solitary, terrestrial carnivores (Beier 1995, McLellan \& Hovey 2001 inter alia). Detection patterns of mature female tiger sharks were consistent with the use of overlapping core areas, which may explain why overlap among individuals was not less than $23 \%$ despite overall wide-ranging, arrhythmic behaviour.

Previous studies have documented clear, diel patterns of tiger shark movements in the remote Northwestern Hawaiian Islands (NWHI) (Tricas et al. 1981, Lowe et al. 2006). The different behavior patterns observed in different areas of the Hawaiian archipelago may indicate that tiger sharks switch movement patterns and foraging strategies to take advantage of seasonally abundant or 'windfall' resources. For example, tiger sharks in the NWHI congregate predictably around small sandy islets each summer to prey on abundant fledging albatross (Phoebastria spp.) and exhibit clear, diel patterns of movement during this period (Tricas et al. 1981, Lowe et al. 2006). Tiger sharks also aggregate to scavenge on large carrion such as dead whales (Dudley et al. 2002). This phenomenon may explain why we were able to catch several sharks simultaneously at the same location and yet not detect these tagged sharks together at the same
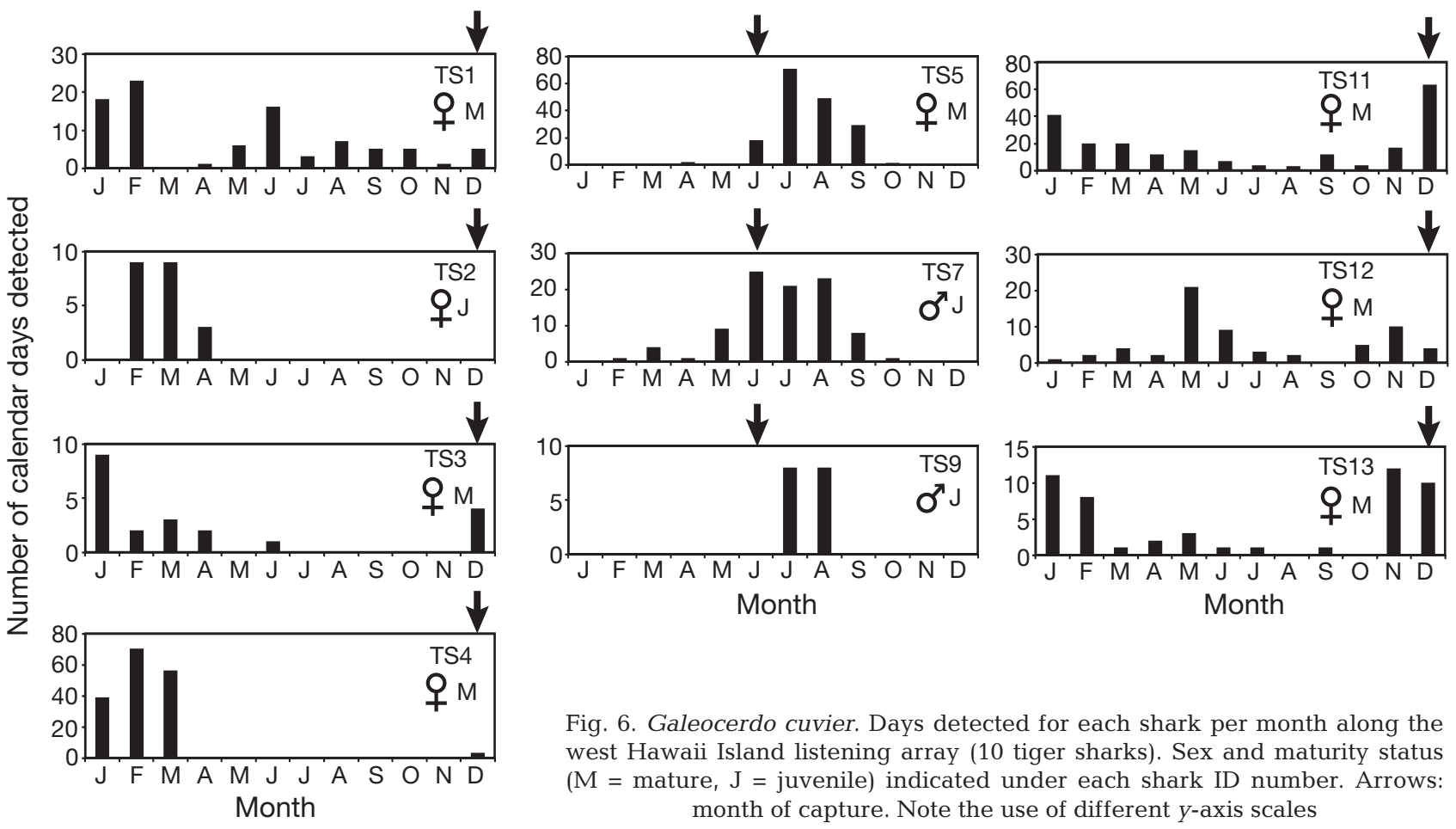

Fig. 6. Galeocerdo cuvier. Days detected for each shark per month along the west Hawaii Island listening array (10 tiger sharks). Sex and maturity status ( $\mathrm{M}=$ mature, $\mathrm{J}=$ juvenile $)$ indicated under each shark ID number. Arrows: month of capture. Note the use of different $y$-axis scales 

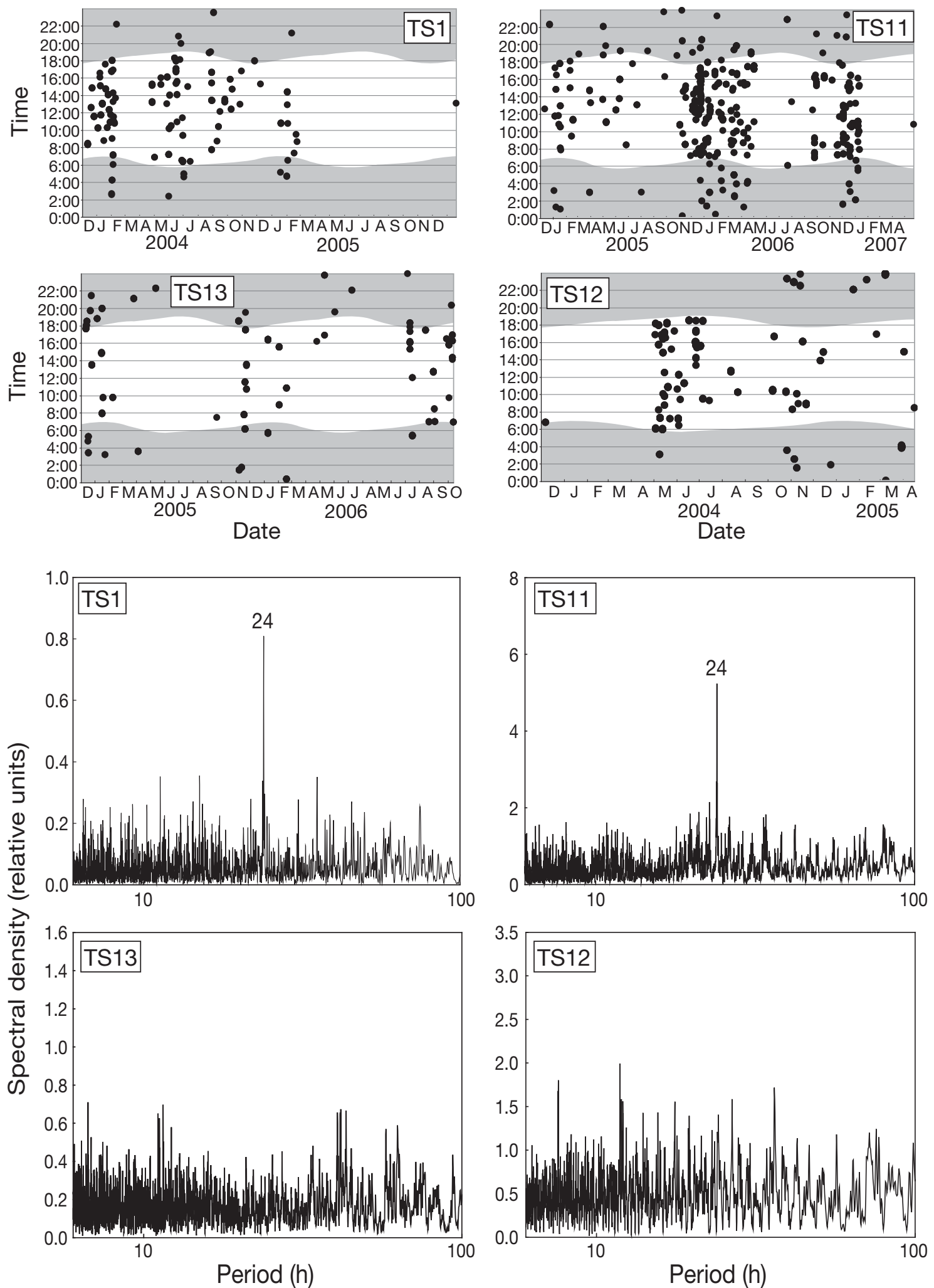

Fig. 7. Galeocerdo cuvier. Top panels: Diel detections (•) of 4 tiger sharks on receivers located along the west Hawaii Island coast from December 2003-May 2007. Shading: nighttime periods. Bottom panels: corresponding spectral analyses (Fast Fourier Transformations) of hourly tiger shark detections along the west Hawaii Island coast. Note the $24 \mathrm{~h}$ peak evident in spectra of sharks TS1 and TS11 in contrast to sharks TS12 and TS13, which showed no such peaks. $x$-axis is a log scale. Note the use of different $y$-axis scales 
locations at the same times during several subsequent years of acoustic monitoring. The baited lines left in situ for $12 \mathrm{~h}$ may have created a 'carrion windfall' detectable by tiger sharks over a wide area (e.g. a current of $1 \mathrm{~km} \mathrm{~h}^{-1}$ could create a $12 \mathrm{~km}$ odor corridor over a $12 \mathrm{~h}$ period), resulting in tiger sharks switching from their general pattern of behavior to converge on the source of carrion.

Prey type and abundance appear to be key factors determining tiger shark foraging strategy. Wideranging and unpredictable movements by solitary individuals may be most effective when hunting riskaverse prey (such as long-lived reef fishes), whereas restricted movements and predictable patterns of behaviour by groups of individuals are evident where food resources are super abundant or where sharks are targeting naïve prey (Lima 2002). Similar prey-driven changes in movement patterns may also occur in white sharks Carcharodon carcharias which exhibit seasonally localized movements around seal colonies (Klimley et al. 2001a,b) but also undertake long-distance, open-ocean migrations to offshore foraging areas (Domeier \& Nasby-Lucas 2008). Abundant seasonal food sources are also known to result in predictable aggregations of terrestrial apex predators that are generally solitary foragers, such as brown bears Ursus arctos horribilis Ord, 1815 at salmon runs or clam beaches (Miller et al. 1997, Smith \& Partridge 2004).

Tiger sharks occasionally bite humans, hence their movements and foraging strategies have public safety and risk-management implications. Our observations of wide-ranging movements and brief, infrequent visits to specific coastal sites reinforce the conclusions of previous studies that culling programs are unlikely to be effective in either catching a shark responsible for an attack or reducing an already low attack risk (2 to 4 attacks $\mathrm{yr}^{-1}$ in Hawaii) (Wetherbee et al. 1994, Holland et al. 1999). There is little evidence linking tiger shark attack risk to diel rhythms (e.g. greater risk at dawn and dusk) in the Main Hawaiin Islands. Tiger sharks were detected inshore at all times of the diel cycle, including among the few individuals that exhibited weak diel patterns in their movements. In Hawaii most $(67 \%)$ shark bites occur during the middle portion of the day, when the majority of in-water recreation occurs (Meyer 2007), suggesting that their timing is primarily a reflection of human activities (Baldridge 1974) rather than intrinsic rhythmicity in the foraging behaviour of tiger sharks. Although our results suggest that in most cases tiger sharks will only remain in an area for a few minutes, we also observed some tiger sharks exhibiting periods of more restricted movements, particularly in the vicinity of Honokohau Harbor. One possible explanation for this is that frequent dumping of fish carcasses into the harbor (C. Meyer pers. obs.) may be switching some sharks from wide-ranging movement patterns associated with hunting risk-averse prey, to more resident behaviour associated with scavenging a predictable source of carrion. It is unclear whether this increases risk to people but it seems prudent to avoid rewarding tiger sharks visiting sites used for ocean recreation. This study demonstrates that extensive listening arrays constructed by informal consortia can provide insights into long-term movement patterns of highly mobile species that would be difficult to reveal using other methods.

Acknowledgements. We thank Kona Village Resort for their generous hospitality in hosting our research team, Kona Fish Company for supplying us with bait and the Hawaii Division of Aquatic Resources for funding this study. We thank the following users of the VR1/VR2 acoustic monitoring system for sharing data from their receivers: S. Beavers (National Park Service), D. Ziemann (Oceanic Institute), G. Crow and M. Heckman (Waikiki Aquarium, University of Hawaii), B. Shumacher (Zoology Department, University of Hawaii), D. Itano (Pelagic Fish Res Program, University of Hawaii). We are grateful to R. Kosaki for providing us with a skiff and assistance with shark fishing and tagging. We thank D. Grubbs for enabling us to tag 2 tiger sharks captured inside Kaneohe Bay, K. Duncan, S. Beavers, R. Gmirkin, T. Eliades and C. Brown for field assistance, and G. and V. Newman for logistical support. We thank J. Won Lee for assistance with data analyses. This work was carried out in accordance with the animal use protocols of the University of Hawaii (protocol \#05-053).

\section{LITERATURE CITED}

Baldridge DH (1974) Shark attack: a program of data reduction and analysis. Contrib Mote Mar Lab 1:1-98

Beier P (1995) Dispersal of juvenile cougars in fragmented habitat. J Wildl Manag 59:228-237

Brown JS, Laundre JW, Gurung M (1999) The ecology of fear: optimal foraging, game theory, and trophic interactions. J Mammal 80:385-399

Chatfield C (2003) The analysis of time series: an introduction, 6th edn. Chapman \& Hall-CRC Press, Boca Raton, FL

Compagno LJV (1984) FAO species catalogue, vol. 4. Sharks of the world: An annotated and illustrated catalogue of shark species known to date. II. Carcharhiniformes. FAO Fish Synop 125:251-655

Connor EF, Simberloff D (1979) The assembly of species communities: chance or competition? Ecology 60:1132-1140

Domeier ML, Nasby-Lucas N (2008) Migration patterns of white sharks Carcharodon carcharias tagged at Guadalupe Island, Mexico, and identification of an eastern Pacific shared offshore foraging area. Mar Ecol Prog Ser 370:221-237

Dudley SFJ, Anderson-Reade MD, Thompson GS, McMullen PB (2002) Concurrent scavenging off a whale carcass by great white sharks, Carcharodon carcharias, and tiger sharks, Galeocerdo cuvier. Fish Bull (Wash DC) 98: 646-649

Gotelli NJ, Entsminger GL (2004) EcoSim: null models software for ecology. Version 7. Acquired Intelligence Inc. \& Kesey-Bean, Jericho, VT. (http://garyentsminger.com/ ecosim/index.htm; accessed November 22, 2008) 
Graham RT, Roberts CM, Smart JCR (2006) Diving behaviour of whale sharks in relation to a predictable food pulse. J R Soc Interface 3:109-116

Heithaus MR (2001) The biology of tiger sharks, Galeocerdo cuvier, in Shark Bay, Western Australia: sex ratio, size distribution, diet, and seasonal changes in catch rates. Environ Biol Fishes 61:25-36

Heithaus MR, Dill LM, Marshall GJ, Buhleier B (2002) Habitat use and foraging behaviour of tiger sharks (Galeocerdo cuvier) in a seagrass ecosystem. Mar Biol 140:237-248

Heithaus MR, Wirsing AJ, Dill LM, Heithaus LI (2007) Longterm movements of tiger sharks satellite-tagged in Shark Bay, Western Australia. Mar Biol 151:1455-1461

Holland KN, Wetherbee BM, Lowe CG, Meyer CG (1999) Movements of tiger sharks (Galeocerdo cuvier) in coastal Hawaiian waters. Mar Biol 134:665-673

Klimley AP, Le Boeuf BJ, Cantara KM, Richert JE, Davis SF, Van Sommeran S, Kelly JT (2001a) The hunting strategy of white sharks at a pinniped colony. Mar Biol 138:617-636

Klimley AP, Le Boeuf BJ, Cantara KM, Richert JE, Davis SF, Van Sommeran S (2001b) Radio-acoustic positioning: a tool for studying site-specific behavior of the white shark and large marine vertebrates. Mar Biol 138:429-446

Kohler NE, Casey JG, Turner PA (1998) NMFS Cooperative Shark Tagging Program, 1962-93: an atlas of shark tag and recapture data. Mar Fish Rev 60:1-87

Kohler NE, Natanson LJ, Pratt HL Jr, Turner PA, Briggs R (1999) The shark tagger -1998 annual summary. National Marine Fisheries Service, Narragansett, FL

Lima SL (2002) Putting predators back into behavioral predator-prey interactions. Trends Ecol Evol 17:70-75

> Lowe CG, Wetherbee BM, Crow GL (1996) Ontogenetic dietary shifts and feeding behaviour of the tiger shark, Galeocerdo cuvier, in Hawaiian waters. Environ Biol Fishes 47:203-212

Lowe CG, Wetherbee BM, Meyer CG (2006) Using acoustic telemetry monitoring techniques to quantify movement patterns and site fidelity of sharks and giant trevally around French Frigate Shoals and Midway Atoll. Atoll Res Bull 543:281-303

McKibben JN, Nelson DR (1986) Patterns of movement and grouping of gray reef sharks, Carcharhinus amblyrhynchos, at Enewetak, Marshall Islands. Bull Mar Sci 38: 89-110

McLellan BN, Hovey FW (2001) Natal dispersal of grizzly bears. Can J Zool 79:838-844

Meyer CG (2007) The impacts of spear and other recreational fishers on a small permanent Marine Protected Area and adjacent pulse fished area. Fish Res 84:301-307

Editorial responsibility: Roger Hughes,

Bangor, UK
Meyer CG, Holland KN, Wetherbee BM, Lowe CG (2001) Diet, resource partitioning and gear vulnerability of Hawaiian jacks captured in fishing tournaments. Fish Res 53:105-113

> Meyer CG, Holland KN, Papastamatiou YP (2007a) Seasonal and diel movements of giant trevally (Caranx ignobilis) at remote Hawaiian atolls: implications for the design of Marine Protected Areas. Mar Ecol Prog Ser 333:13-25

Meyer CG, Papastamatiou YP, Holland KN (2007b) Seasonal, diel and tidal movements of green jobfish (Aprion virescens, Lutjanidae) at remote Hawaiian atolls: Implications for Marine Protected Area design. Mar Biol 151: 2133-2143

Miller SD, White GC, Sellers RA, Reynolds HV and others (1997) Brown and black bear density estimation in Alaska using radiotelemetry and replicated mark-resight techniques. Wildl Monogr 133:3-55

Papastamatiou YP, Wetherbee BM, Lowe CG, Crow GL (2006) Distribution and diet of four species of carcharhinid shark in the Hawaiian Islands: evidence for resource partitioning and competitive exclusion. Mar Ecol Prog Ser 320: 239-251

> Simpfendorfer C (1992) Biology of tiger sharks (Galeocerdo cuvier) caught by the Queensland Shark Meshing Program off Townsville, Australia. Aust J Mar Freshwater Res 43:33-43

Smith TS, Partridge ST (2004) Dynamics of intertidal foraging by coastal brown bears in southwestern Alaska. J Wildl Manage 68:233-240

- Tricas TC, Taylor LR, Naftel G (1981) Diel behavior of the tiger shark, Galeocerdo cuvier, at French Frigate Shoals, Hawaiian Islands. Copeia 904-908

Wetherbee BM, Lowe CG, Crow GL (1994) A review of shark control in Hawaii with recommendations for future research. Pac Sci 48:95-115

> Wetherbee BM, Crow GL, Lowe CG (1996) The biology of the Galapagos shark, Carcharhinus galapagensis, in Hawaii. Environ Biol Fishes 45:299-310

> Wetherbee BM, Crow GL, Lowe CG (1997) Distribution, reproduction and diet of the gray reef shark Carcharhinus amblyrhynchos in Hawaii. Mar Ecol Prog Ser 151:181-189

Whitney NM, Crow GL (2007) Reproductive biology of the tiger shark (Galeocerdo cuvier) in Hawaii. Mar Biol 151:63-70

- Wirsing AJ, Heithaus MR, Dill LM (2006) Tiger shark (Galeocerdo cuvier) abundance and growth in a subtropical embayment: evidence from 7 years of standardized fishing effort. Mar Biol 149:961-968

Submitted: February 13, 2008; Accepted: January 29, 2009 Proofs received from author(s): April 3, 2009 